\title{
Design and Structural Analysis of Clutch Hub Using CAD
}

\author{
Shrikant G. Dhumale ${ }^{1}$, Shubhangi G. Kamble ${ }^{2}$ \\ ${ }^{I}$ M.Tech Student \\ Government College of Engineering, Amravati, India, 444604 \\ ${ }^{2}$ Assistant Professor, Professor \\ Government College of Engineering, Amravati, India, 444604
}

Received on: 09 April,2021, Revised on: 13 May,2021, Published on: 15 May, 2021

\begin{abstract}
Clutch is an important part in the transmission system of the automobiles and transfers power to the driven shaft smoothly. The conventional designing carried various flaws and was difficult to conceptualize from $2 D$ drawings. But the use of solid modeling techniques made it very much simpler for the designer and the analysis software's are used to analyze the parts without actually fabricating the product which indirectly saves money and material as well as time improving the productivity of the working. We can analyze various products precisely in the software and improve the design as per the requirement and values obtained. This paper studies the design of the clutch hub using solid modeling (CATIA) and the static structural analysis of clutch hub using ANSYS. The material used for the analysis purpose is $A B S$. As, to explore the working area of the ABS and due to it's high strength to weight ratio and to test the performance of the clutch hub at the high torque. The study shows the efficient working of ABS made clutch hub and it's static structural analysis.
\end{abstract}

Keywords- ABS, Analysis, ANSYS, CATIA, Clutch Hub.

\section{I- INTRODUCTION}

C lutch is a machine part which is used to transfer the motion or torque from driving shaft to the driven shaft smoothly. In automobiles we can see the various examples of the clutches and it's various types such as single plate clutch, multi plate clutch, centrifugal clutch and cone clutch likewise. As to increase the speed of the vehicle we need to change the gear according to the need and also idle gearing is required, at that time clutch plays an important role in the engine transmission. In the two wheeler SI engine vehicles we generally observe multi plate type wet clutch. The multi plate type wet clutch consist of various parts like clutch housing, pressure plate, friction plate, clutch plate, Clutch Hub, compression spring, etc. As the clutch is used to engage and disengage the flywheel, and undergoes lot of torque and pressure it needs to be designed precisely. The smooth transfer of power is the main aim of the clutch. Various types of materials are used for the clutches like steel and it's alloys. The material plays important role in the performance of the clutch. In this work we have used ABS material due to its high strength to weight ratio and it can also be $3 \mathrm{D}$ printed. As we know the Additive manufacturing is rapidly growing as the manufacturing technique. $\mathrm{ABS}$ is a thermoplastic material and has excellent engineering properties. From the analysis we will be able to check the whether the material can substitute the metal alloy.

An efficient and reliable analysis can also be done on mechanical clutches using computer modeling. Also, stress analysis and reduction of forces in single plate type of clutch of automobile can be done with the help of software approaches. Based on such methodology an efficient and reliable design of clutch can be found and proper material also be selected from analysis approach 


\section{International Journal of Innovations in Engineering and Science, www.ijies.net}

[1][2]. Improved transmission efficiency can be obtained from the design changes and reducing error, such that whole assembly can be designed to improve the working efficiency again we can analyze various materials and composites in the interface [3][4]. Designing and analysis process we can check various parameters which influence the performance of the product like equivalent stress, strain, deformations, etc and improve our design according to the need [5][6]. The various studies shows that design and analysis can be done on various kinds of transmission parts and from the data obtained we can optimize our design and save cost and time as well [7][8].

\section{II- CLUTCH HUB}

Clutch hub or clutch boss is a machine part on which the clutch plate and friction plate are mounted. The clutch hub rotates when the clutch gets engaged to the flywheel and due to spring force it starts rotating. The part we are designing is shown in the below figure 1. (Hero Splender Clutch Hub). The vehicle transmits a torque around 8.05 $\mathrm{Nm}$. So the clutch hub provides the motion to the friction and clutch plate and friction plate. While the clutch is important part of the clutch assembly. While engaging and disengaging the clutch hub rotates with the same torque as that of the flywheel. And due to the friction plate and clutch plate are mounted on hub, it undergoes the tensile force and continuous rotation may result in failure and fatigue. So, the clutch hub plays important role in transmission and does not let the plates slip out of the grooves.

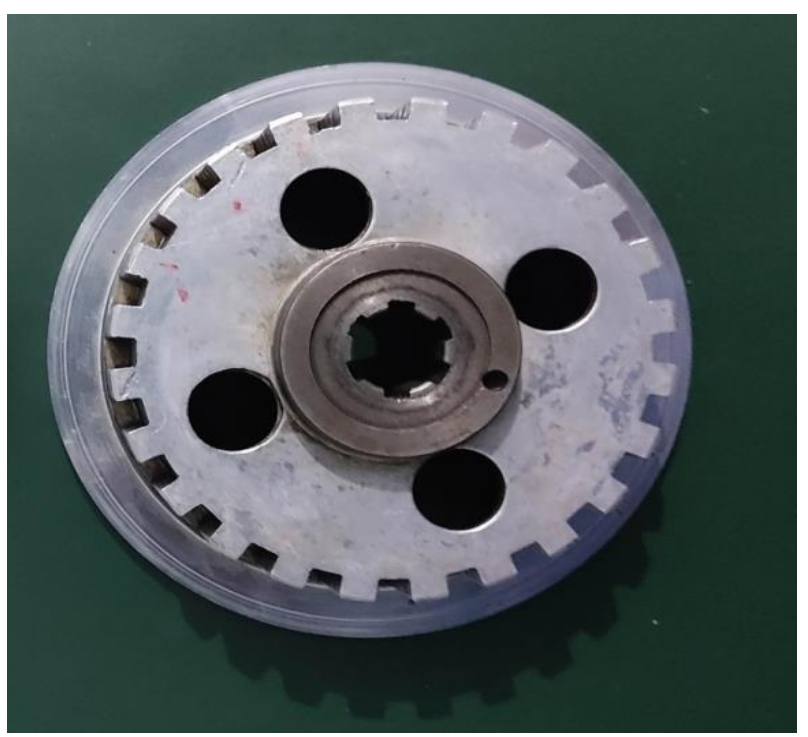

Fig. 1- Clutch Hub (Hero splender)

\section{III- MATERIAL}

Acrylonitrile Butadiene Styrene (ABS) plastic<smiles>C=CC#N</smiles><smiles>C=CC=C</smiles><smiles>CCCC(C)C(C)CC</smiles>

Fig 2 : Monomers of Acrylonitrile, Butadiene, and Styrene (left to right at top), and one possible arrangement of these monomers combined as ABS (bottom)

Acrylonitrile Butadiene Styrene is a common polymer of thermoplastic type and also 3D-printing filament material. ABS has a high impact resistance and amorphous type of polymer in nature. As shown in above figure. 2 it is made with the combination of three monomers (i.e acrylonitrile, butadiene, styrene). The fabrication of the ABS parts can be done using 3D printing, injection molding, extrusion, etc. It is cost efficient and effective at the same time. The various properties of the ABS are shown in the following table 1. ABS has excellent mechanical properties to withstand our application use.

Table 1- Properties of ABS

\begin{tabular}{|c|c|}
\hline Material Properties & ABS \\
\hline Desnsity & $1.01 \mathrm{e} 3-1.21 \mathrm{e} 3 \mathrm{~kg} / \mathrm{m} 3$ \\
\hline Young's Modulus & $1.79-3.2 \mathrm{GPa}$ \\
\hline Yield Stress & $29.6-48 \mathrm{MPa}$ \\
\hline Flexural Modulous & $1.6-2.4 \mathrm{GPa}$ \\
\hline Elongation Yield & $1.7-6 \%$ \\
\hline Poisson's Ratio & 0.4089 \\
\hline
\end{tabular}




\section{International Journal of Innovations in Engineering and Science, www.ijies.net}

\section{IV- METHOLOGY}

Various studies have been done on the performance of the clutch plate, friction plates. We have designed the clutch hub with the help of theoretical dimensions and the solid modeling is done in CATIA after the designing the static structural analysis is done of the parts for the required boundary condition. The clutch hub we are analyzing is of Hero Splendor. The material used for the analysis purpose is $\mathrm{ABS}$ and the equivalent stress, strain values are obtained for the same. The process flowchart of design and analysis process is shown below in Fig 3 .

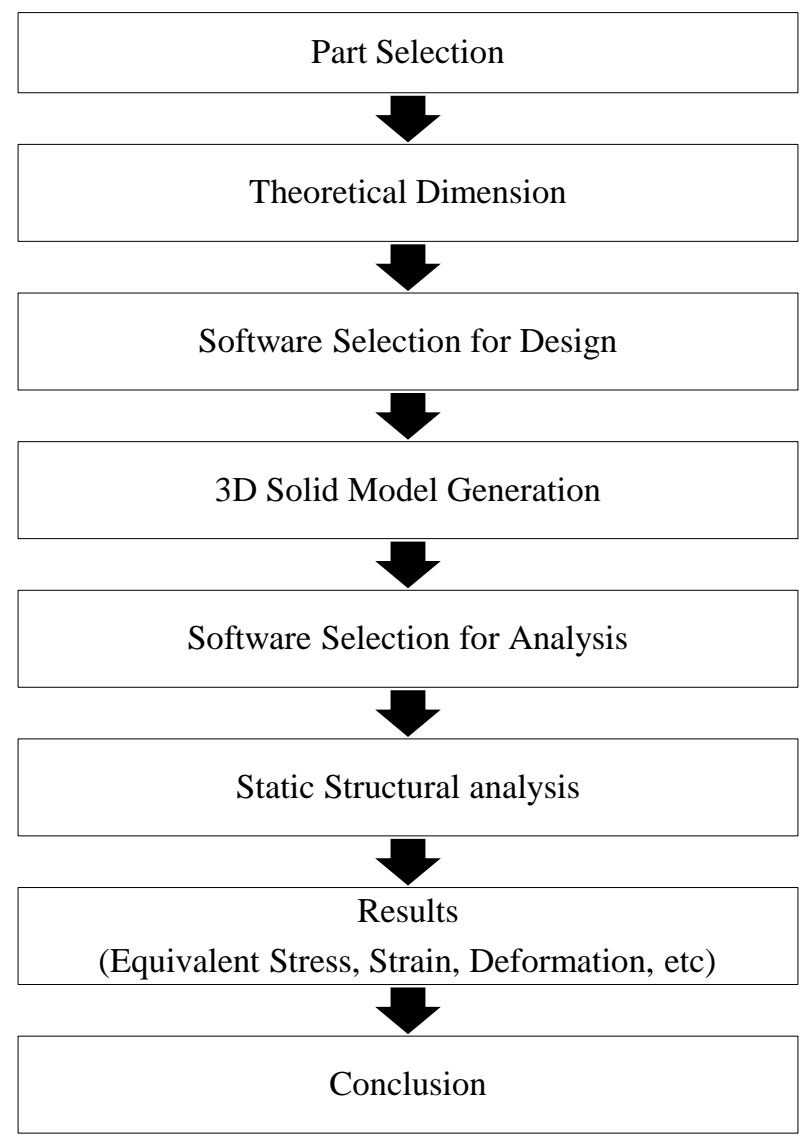

Fig 3- Flow chart of Methodology

\section{V- STRUCTURAL ANALYSIS}

Structural analysis is nothing but a combination of mathematical calculation and some physical laws to predict the structural behavior of the product. The structural analysis judge the ability of the material or product to withstand various loads and the behavior of the product under various loads. The most common software used for the analysis is ANSYS. Structural analysis incorporates the various fields of dynamics and mechanics and various theories of failure. We can see the analysis as the method to predict the behavior of the product or design before actually producing and check the soundness and safety of the design. It not only saves the cost but also saves the time and results obtained are close to the actual working result. Basically two types are analysis are popular among the researchers and are:

1. Static Structural Analysis

2. Finite Element Analysis

\section{VI- DESIGN OF THE CLUTCH HUB}

The design of the wet sump multi plate type clutch hub(Hero Splendor) is done using CATIA V5 R17 software and the solid model is shown below in figure 4 and figure 5. The calculation taken is theoretical and design is made.

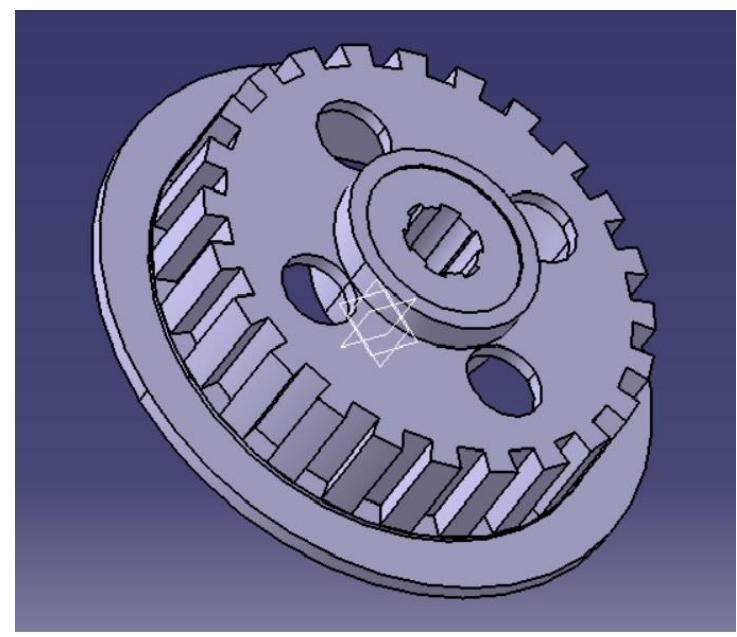

Fig 4- Solid Model of Clutch Hub (Front View)

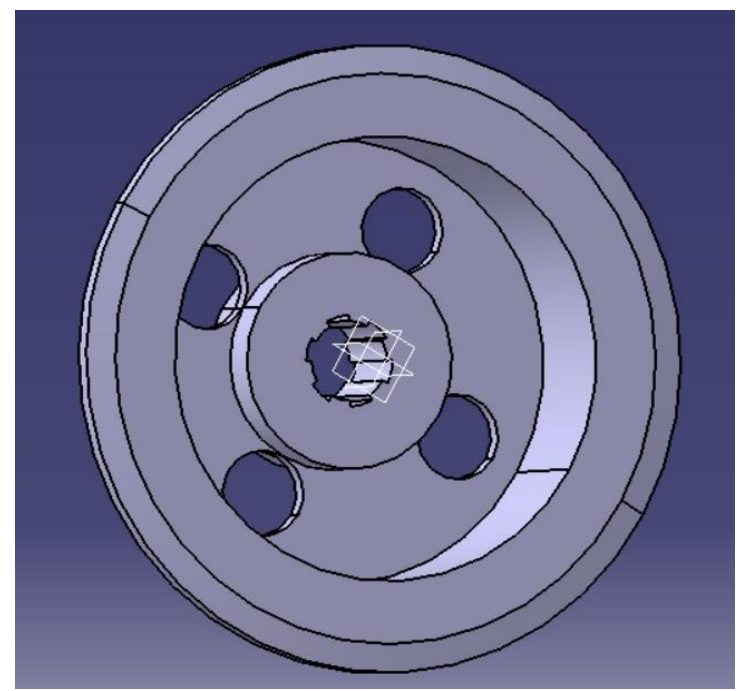

Fig 5- Solid Model of Clutch Hub (Back View) 


\section{International Journal of Innovations in Engineering and Science, www.ijies.net}

\section{VII- ANALYSIS RESULT OF CLUTCH HUB}

The analysis of the part is done by using ANSYS R20 software and the values of Equivalent Stress and total deformation are found. The Design and working specification are shown in the following table 2 .

Table 2- Working parameters of clutch hub.

\begin{tabular}{|c|c|}
\hline Properties & Values \\
\hline Maximum Torque & $8.05 \mathrm{Nm}$ \\
\hline Maximum Power & $8.02 \mathrm{PS}$ \\
\hline Rotational Speed & $6000 \mathrm{RPM}$ \\
\hline
\end{tabular}

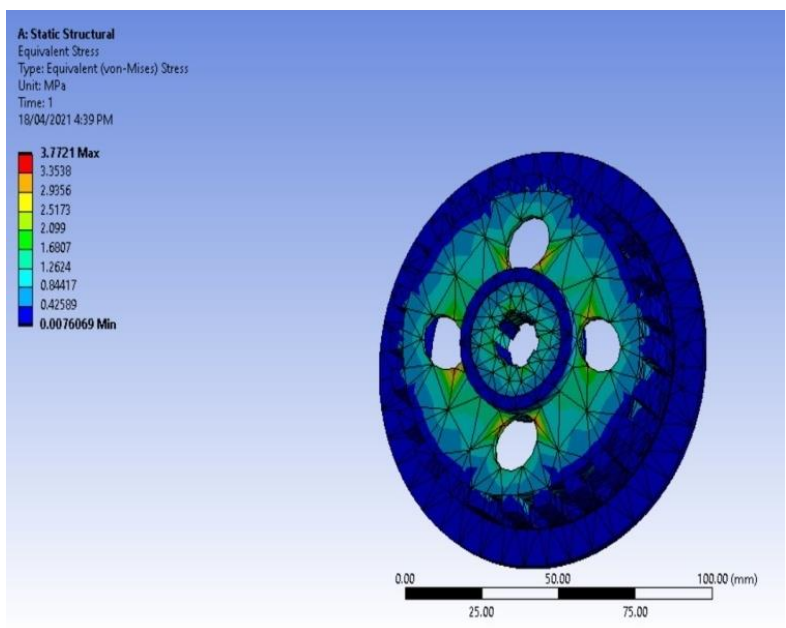

Fig 6- Equivalent Stress

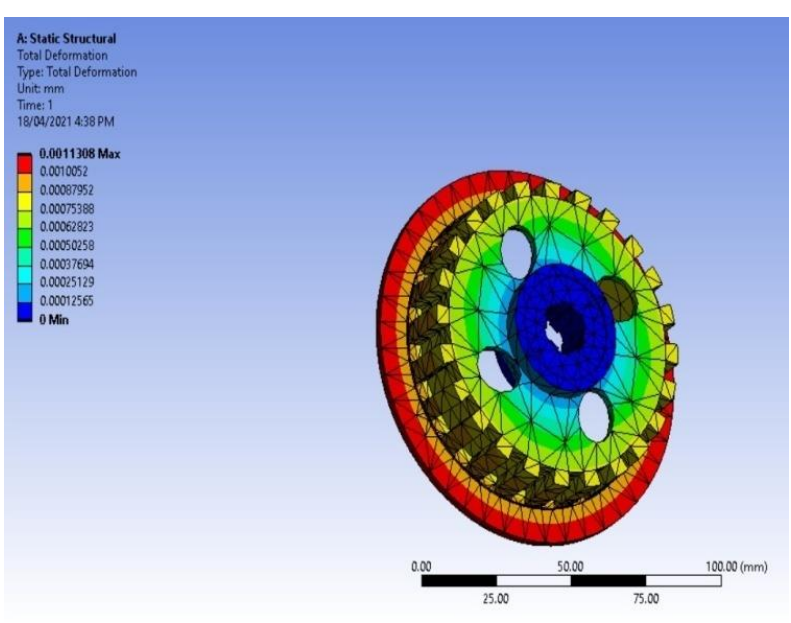

Fig 7- Total Deformation

\section{VIII- CONCLUSION}

In this study work, we have designed a solid model of the clutch hub of wet sump multi plate type clutch hub and analyzed the design in ANSYS R20 workbench for the ABS material. The Equivalent Stress obtained from the analysis is found to be $3.7721 \mathrm{MPa}$ and the Total Deformation obtained is around $0.0011308 \mathrm{~mm}$. From the results obtained we can conclude that design is safe and $\mathrm{ABS}$ can be used in the engine transmission like application. While the production of the part can be done by additive manufacturing technique as the ABS is thermoplastic material and finds application in that field. Also, the design is optimized from the original design and safe as well. Present study explore the use of ABS in transmission system and the simplicity of the process of designing and analysis.

\section{REFERENCES}

[1] Nishant Dhengre, Ashish Mogra, Ankit Gupta, "Investigating Behaviour of Multi-Clutch Plate Frictional Materials using ANSYS" International Journal of Applied Engineering Research, ISSN 0973-4562 Volume 13, Number 16 (2018) pp. 12657-12662.

[2] Vishal J. Deshbhratar, Nagnath U. Kakde, "Design and Structural Analysis of Single Plate Friction Clutch". International Journal of Engineering Research \& Technology (IJERT), Vol. 2 Issue 10, IJERT ISSN: 2278-0181 October 2013.

[3] S. Gouse seema begum, A. Balaraju, "Design and Analysis of Friction Clutch Plate using Ansys". International Journal of Advanced Engineering Research and Science (IJAERS,) [Vol-2, Issue-5, May-2015] ISSN: 2349-6495.

[4] Rahul A. Raikwar, Suhas Rewatkar, Santosh Kumar, "Study the Design Aspects and Function of Wet Type Multi-Plate Clutch". IJSTE - International Journal of Science Technology \& Engineering, Volume 2 Issue 4 ISSN (online): 2349-784X October 2015.

[5] Sunny Narayan , Ivan Grujic , Nadica Stojanovic at. el. “ Design and analysis of an Automotive Single Plate Clutch". Mobility \& Vehicle Mechanics, Vol. 44, No. 1, (2018), pp 13-26 DOI: 10.24874/mvm.2018.44.01.02 UDC: 539.379(086.48) April 2018.

[6] Rajesh Purohit, Pooja Khitoliya, Dinesh Kumar Koli, "Design and Finite Element Analysis of an Automotive Clutch Assembly". ICMPC 2014.

[7] MAY THIN GYAN, HLA MIN HTUN, "Design and Structural Analysis of Single Plate Clutch". IJSETR, ISSN 2319-8885 Vol.03,Issue 10 May-2014.

[8] Kunchala Brahmaiah, O Hemlatha, "Design and Analysis of Friction Clutch Plate using different materials". International Journal of Management, Technology And Engineering, Volume 8, Issue X, ISSN NO- 2249-7455 OCTOBER 2018.

[9] N. A. Barve, M. S. Kirkire, "Analysis of Single Plate Friction Clutch Using Finite Element Method". International Journal of Advances Scientific research and engineering Trends, Volume 2 Issue 11, ISSN (Online) 2456-0774 JUNE 2017. 